\title{
МЕТОД ПРОКАТУВАННЯ КРАЙОК МІДІ ДЛЯ ЗМЕНШЕННЯ РИЗИКУ УТВОРЕННЯ ЕВТЕКТИК ЗВАРНОГО ШВА
}

Розвиток сучасних технологій зварювання різнорідних деталей залежить від можливості керування процесом з метою передбачення високої якості зварного шва. Розробка процесу зварювання та оперативне корегування технології дозволяє одержати зварні шви з високою працездатністю впродовж експлуатації.

При аналізі основних хімічних елементів зварювання міді зі сталлю (міді і заліза) відомо, існують відмінності їх властивостей. Особливості зварювання міді із сталлю, які вивчались і визначені науковцями такі [1-5]:

- низька розчинність міді в залізі і заліза в міді;

- відмінності в температурі плавлення і кипіння, теплоти перетворень і випарюваній;

- відмінності в складі, структурі і властивостях металів, які з'єднуються при зварюванні;

- можливість утворення в зоні сплавлення міді із сталлю крихких кристалізаційних і дифузійних прошарків які виникають із-за міжкристалітного проникнення міді в сталь;

- створення в зварному шві зовсім нових фазових і структурних складових, які відсутні у вихідних металах;

- широкий температурний діапазон кристалізації сплавів міді при зварюванні, який сприяє утворенню дефектів зварювання - гарячих тріщин;

- існування температурного інтервалу провалу пластичності мідних сплавів і збільшення крихкості;

- висока спорідненість міді до кисню, причому вона збільшується з-за розчинів між рідким металом і $\mathrm{Cu}_{2} \mathrm{O}$;

- 3-за виділення водню з рідкої міді є можливість утворення несуцільностей - пор у металі зварного шва, при охолодженні і кристалізації.

Незважаючи на те, що мідь і залізо мають параметри кристалічних грат дуже близькі (мідь ГКЦ $a=0,36150$ нм, та залізо ГКЦ $a=0,3656$ нм), 3-за своїх термодинамічних та теплофізичних властивостей - це різнорідні метали, тому дуже важливо урахувати саме їх відмінності.

Засоби і методи урахування теплофізичних властивостей наведені у працях науковців [6-8]. Задля зниження ризику виникнення кристалізаційних прошарків необхідно виконувати методи регулювання термічного стану різнорідних деталей при зварюванні. Найбільш перспективними методами вважаються методи регулювання термічного стану окремо для стальної і мідної деталі $[9,10]$. Крім того, доведено науковцями, що підвищення вмісту заліза на межі сплавлення зварного шва приводить до підвищення кількості дендритних включень. На (рис. ) приведені фото підвищеної кількості дендритних включень та фото зниженої кількості. При дослідження встановлено, що мікроструктура лінії сплавлення зварного шва має нерівномірний характер. Але дендритна будова сталі превалює тим більше, чим далі від лінії сплаву. Підвищення міцності зварного шва за рахунок кількості дендритних включень заліза призводить до одночасного зниження пластичності зварного з'єднання, таким чином - знижуючи вміст заліза в зварному шві, можна набути необхідних властивостей (пластичність) біляшовної зони і самого шва.

Визначена доцільність регулювання термічного стану деталей при зварюванні з урахуванням методику аналізу конструктивного виконання зварних вузлів та особливостей експлуатаційних навантажень зварного з'єднання [11, 12]. 


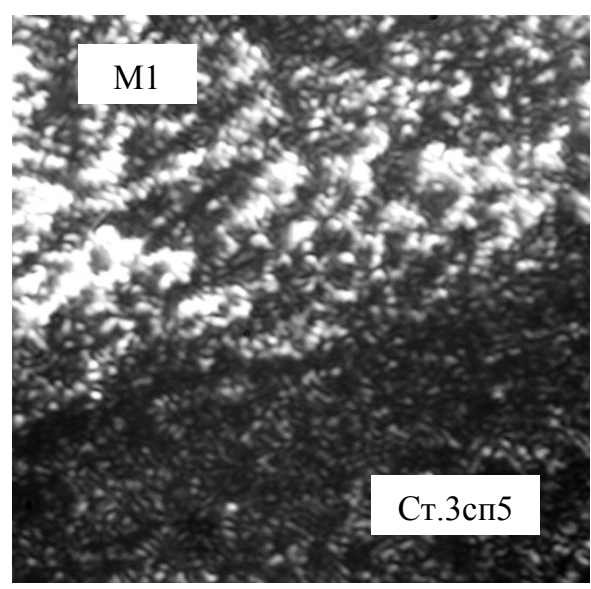

$\times 600$

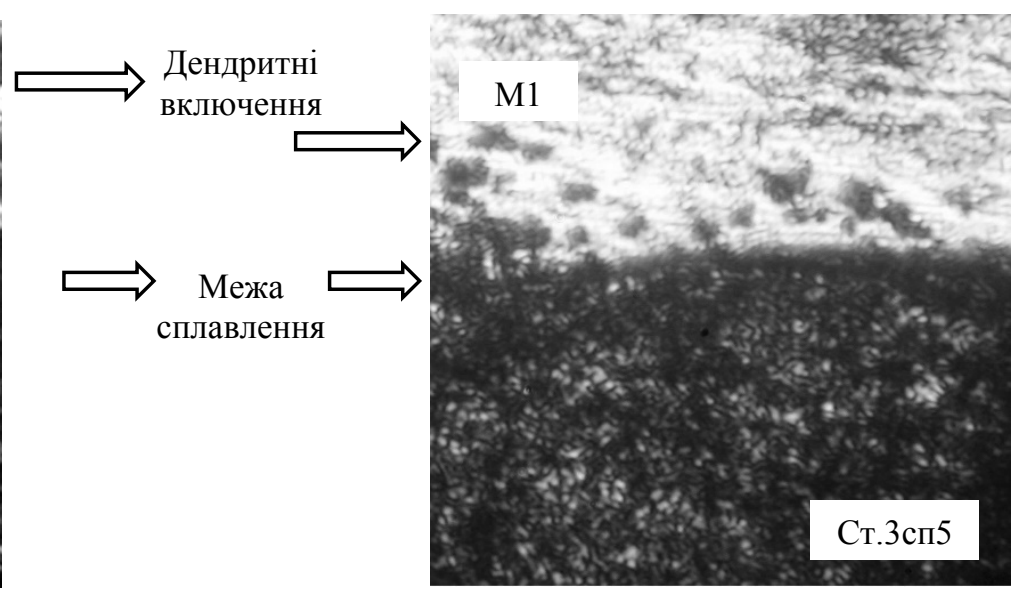

$\times 600$

Рис. 1. Дендритні включення на межі сплавлення

Виконані дослідження впливу геометричних факторів зварного шва при підготовки крайок деталі перед зварюванням. Особливо схильні до утворення кристалізаційних тріщин ті мідні сплави які мають евтектику і перитектику. На утворення тріщин впливає наявність евтектики і низька розчинність легуючого елементу. Наприклад, в мідних сплавів з киснем, сіркою, бором (температура евтектики відповідно $1065{ }^{\circ} \mathrm{C}, 1067{ }^{\circ} \mathrm{C}, 1060{ }^{\circ} \mathrm{C}$ ), причому гранична розчинність цих елементів невелика $(\leq 0,005 \%, 0,002 \%, 0,08 \%)$. У зв'язку з малою розчинністю такого роду хімічних елементів при зварюванні утворюються структури псевдоевтектики $\mathrm{Cu}_{2} \mathrm{O}, \mathrm{Cu}_{2} \mathrm{~S}, \mathrm{Cu}_{2} \mathrm{~B}$. Такі хімічні сполуки добре змочують кордони зерен і при кристалізації матричної фази - сталі, рідка мідь проникає в мікротріщини, заповнюючи розклинює їх в процесі термічної напруги розтягування. Таким чином, адсорбція при зварюванні знижуючи вільну поверхневу енергію (при контакті з речовинами здібними до дії на міжфазній поверхні) сприяє деформації і утворенню дефектів в твердих тілах і кінець кінцем до їх руйнування. Встановлена необхідність виконання кутів підготовки крайок при зварюванні міді і сталі окремо для міді $40^{\circ} \div 44^{\circ}$, а для сталі $16^{\circ} \div 18^{\circ}$. Кут підготовлення крайок зварювання різнорідних металу визначається залежно від зворотнопропорційного відношенню коефіцієнтів теплопровідності металів, які зварюються $[13,14]$. На (рис. 2) наведено фото мікроструктури з евтектичними утвореннями по межах зерен міді.

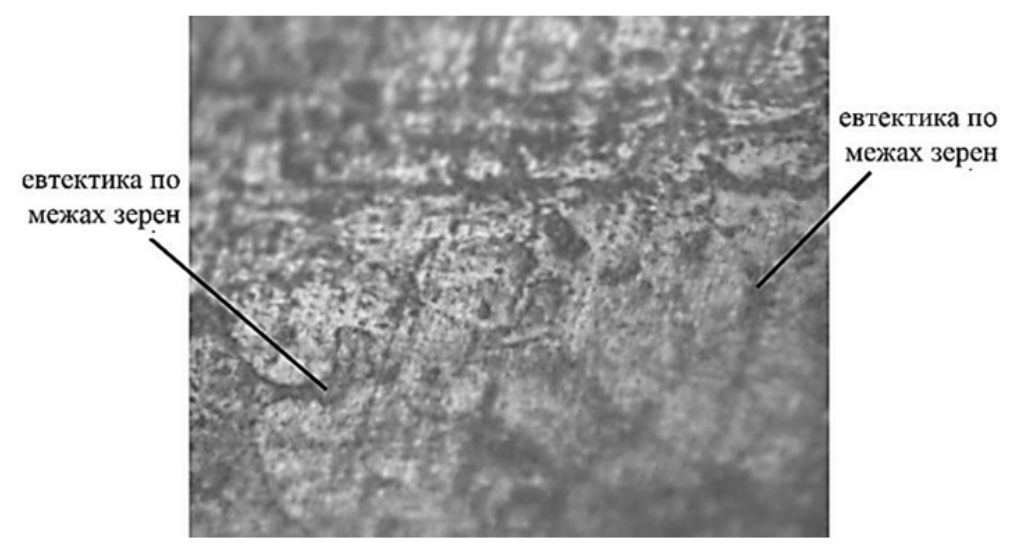

Рис. 2. Мікроструктура з евтектикою $\mathrm{Cu}-\mathrm{Cu}_{2} \mathrm{O}$ по межах зерен міді

Визначена необхідність підготовку крайок міді перед зварюванням виконувати методом ударно-пластичного деформування. Збільшуючи зовнішнє навантаження (підвищуючи частоту ударів і силу удару) атоми зміщуються з положень стійкої рівноваги на відстані, що значно перевищують міжатомні. Після зняття навантаження атоми займають нові місця стійкої рівноваги, тому геометрична форма деталі (кромки зварювальних деталей) 
не відновлюється [15]. Пластична внутрішньокристалітна деформація в окремо взятому зерні відбувається в основному за рахунок ковзання одних тонких атомних шарів кристаліту відносно інших. При деформуванні міді ударними навантаженнями іiі пластична деформація може розвиватися також за рахунок двійникування, в результаті якого, частина кристаліту, що зміщується, займає положення дзеркального віддзеркалення його недеформованої частини. При виконанні оброблення кромки міді способом ударної пластичної деформації в металі виникають додаткові дислокації, утворюються уламки кристалітів, які, утрудняючи подальшу деформацію, викликають збільшення міцності і твердості металу, зменшення пластичності і зміну його фізичних і хімічних властивостей.

Такі внутрішньокристалічні зрушення міді заважають створенню евтектичних плівок, що розділяють зерна металу, з врахуванням дифузії міді в сталь на міжфазному кордоні. Хiмічний склад металу не міняється [15].

Перспективним методом підготовки крайок міді і більш продуктивним $є$ метод прокатування. Прокатування крайок міді приводить до анізотропії механічних властивостей і створенню поверхневого шару наклепаного металу який заважає при зварюванні створенню евтектичних плівок.

В рамках аналізу напружено-деформованого стану металу при прокатці бічних крайок був виконаний розрахунок з використанням методу скінченних елементів в системі Abaqus CAE. Відповідна розрахункова схема, яка представляла собою робочий валок і стрічку, представлена на рис. 3.

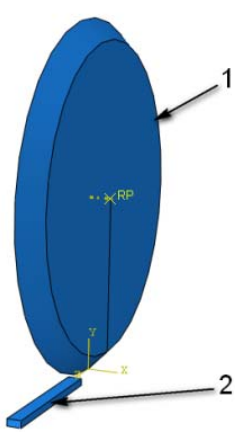

a

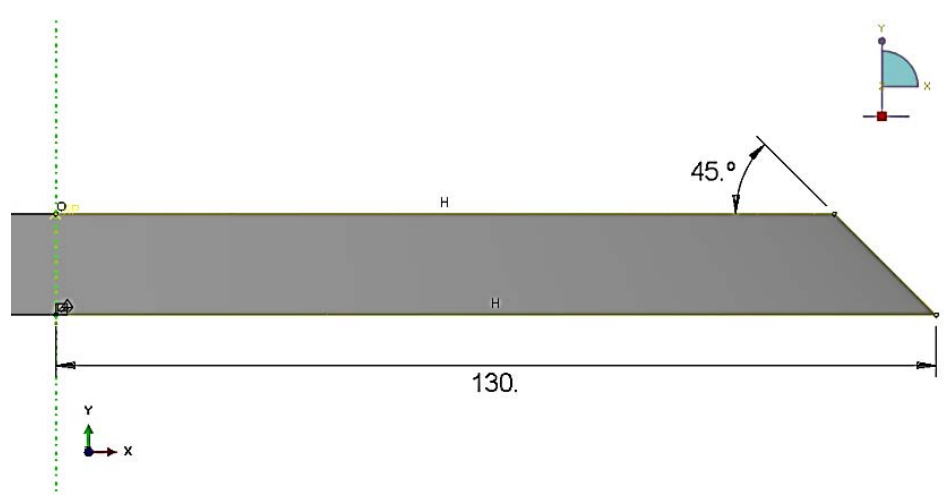

6

Рис. 3. Розрахункова скінченно-елементна модель процесу прокатки бічних крайок стрічки (1 - валок; 2 - стрічка):

а - збірка; б - форма валку

Відповідно до розрахункової схеми (рис. 1) діаметр робочих роликів був прийнятий рівним 260 мм $з$ твірною калібру $45^{\circ}$. Безпосередньо моделювання процесу правки було виконано для листа товщиною 5 мм. Матеріал був прийнятий 3 властивостями пружності та плинності для міді М1. Вихідна скінченно-елементна модель має наступні граничні умови: валок має одну обертальну ступінь свободи, нижня і бічна поверхні стрічки мають можливість переміщатися тільки уздовж осі прокатки. У розрахунку використовувалася модель класичної пластичності металу.

Контакт між стрічкою і валком задавався за допомогою моделі контакту «Поверхня до поверхні» шляхом завдання коефіцієнта тертя $\mu=0,2$.

Робочий валок приводився в обертання з кутовою швидкістю 0,77 рад / сек. Швидкість руху стрічки прийнята рівною 100 мм / с. Час кроку був прийнятий 1,0 c.

Для оцінки отриманих результатів вихідними в даному випадку параметрами були обрані проекції реакцій в контрольних точках валка в глобальній системі координат RF2, RM1, а також переміщення, деформації та напруження в вузлах кінцевих елементів стрічки. Для дослідження процесу прокатки стрічку розбивали на різну кількість елементів, a саме: уздовж стрічки на сітку з кроком 2 мм, за перерізом - 0,5 мм. 
На рис. 4 зображено результати розрахунку процесу прокатки крайок мідної стрічки при різних обтисненнях, а саме $40 \%, 60$ \% і 80 \%, що відповідає впровадженню валка з клиновою поверхнею калібру на 2, 3 і 4 мм. Як видно з результатів розрахунку оптимальним обтисненням є 60 \% (3,0 мм), що практично не призводить до втрати форми стрічки та пластична деформація не перевищує 0,8 .

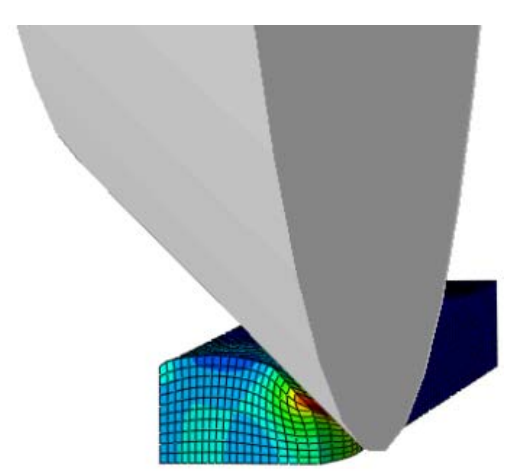

a

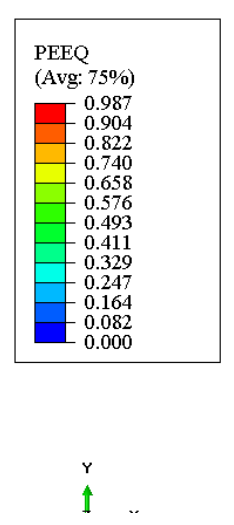

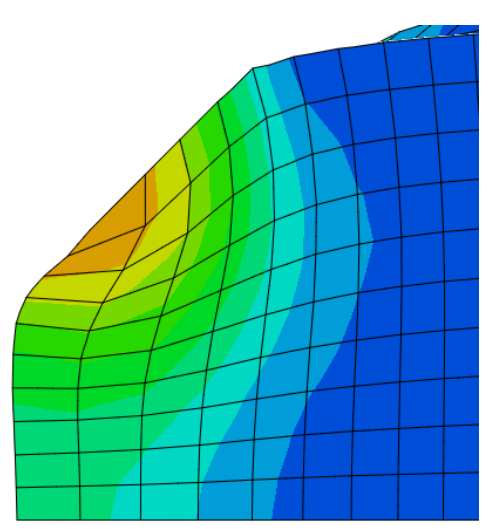

B

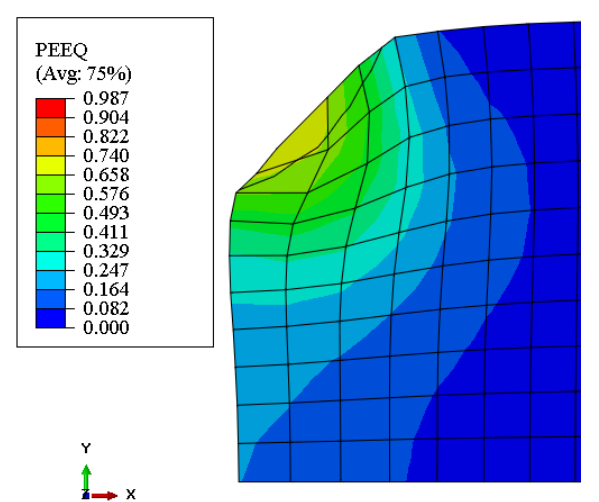

6

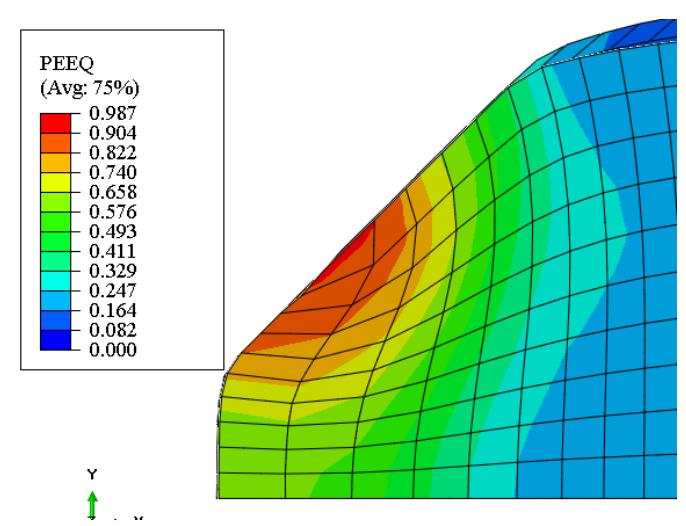

$\Gamma$

Рис. 4. Розрахункові поля еквівалентних пластичних деформацій при прокатуванні крайок міді в залежності від обтиснення:

a - загальний вид; впровадження клину на: 6 - 2,0 мм; в - 3,0 мм; г-4,0 мм

Також при розрахунках були визначені енергосилові параметри процесу, які склали: сила прокатки - 52 кН, момент прокатки 940 Нм (рис. 5).

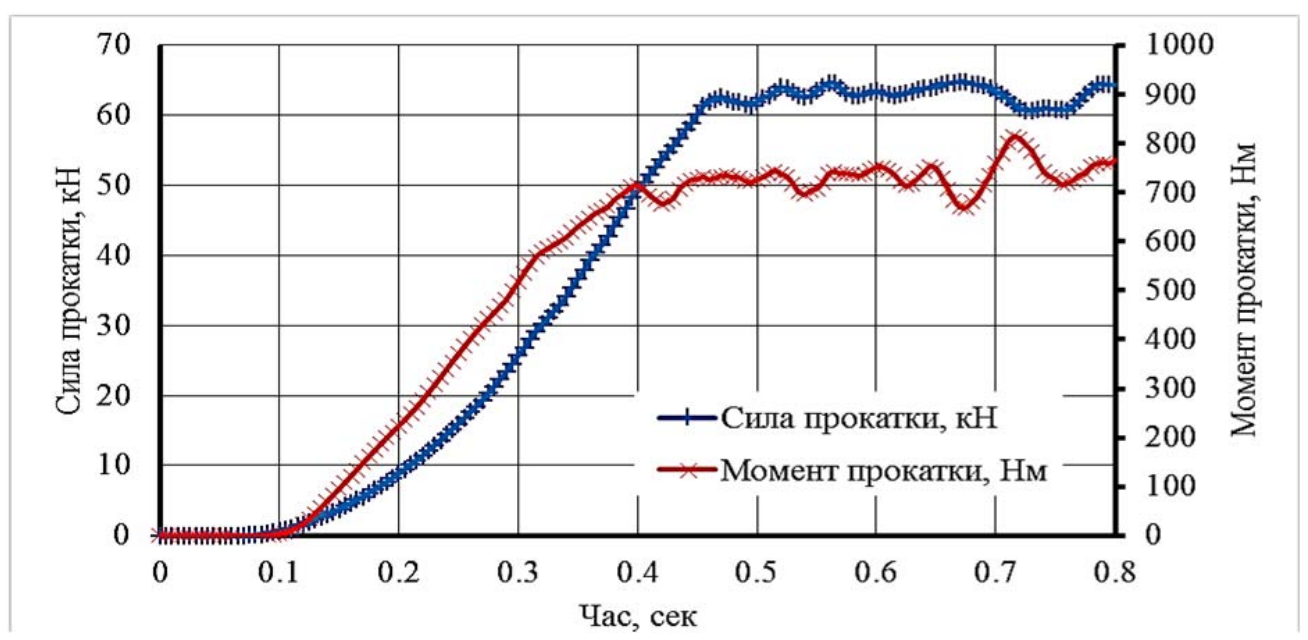

Рис. 5. Енергосилові параметри при прокатуванні крайок міді 


\section{ВИСНОВКИ}

Визначена необхідність використання геометричних методів регулювання термічного стану зварних деталей. Підтверджено доцільність підготовки крайок деталей методом ударно-пластичного деформування. Експериментально доведено необхідність зниження дендритних включень на межі зварного шва з метод підвищення пластичних властивостей і зниження ризику утворення кристалізаційних тріщин. При прокатці крайок мідної стрічки товщиною 5,0 мм визначено розрахунковим шляхом раціональне обтиснення, яке склало $60 \%$, при цьому енергосилові параметри прокатки склали наступні значення: сила -52 кН, момент 940 Нм.

\section{СПИСОК ВИКОРИСТАНОЇ ЛІТЕРАТУРИ}

1. В. В. Рыбин, А. Е. Вайнерман, А. В. Баранов [и др.] Исследование особенностей и разработка прогрессивных технологий сварки медных сплавов со сталями и наплавки медных сплавов на стали. Bonpocbl мameриаловедения. 2006. 1. С. 220-229. ISSN 1994-6716.

2. Илюшенко В. М., Босак Л. К., Гришин Л. И. Автоматическая сварка под флюсом меди со сталью больших толщин. Киев. : Международная ассочиаџия «Сварка». Сварка и наплавка меди и ее сплавов. Составители : В. М. Илюшенко, Е. П. Лукьянченко, 2013. С. 88-90.

3. Oleksiak B., Siwiec G., Blacha A. and Lipart J. Influence of iron on the surface tension of copper. International Scientific Journal. 2010. vol. 44. pp. 39-42.

4. Ding Weie. Heilogjiang kcji xueyuan xuebao. Institute of Science and Technology. 2003. V. 13, N4. P.16-18.

5. G. Arjun, J. R. Atheena, V. Nithin and others. Welding Feasibility of Copper and Mild Steel Using TIG Welding. 7 Department of Metallurgy, Amal Jyothi College of Engineering, Koovapally, Kanjirapally, Kerala. Proc. of the Nat. Conference on Futuristic Advancements in Mechanical Engineering (FAME-2K16) : Thalassery. 2016. August, P. 325-326.

6. Pashkov I., Kustova O., Vetrova J. Phenomenon of interaction between the solder melts on the basis of copper and the steel detail surface. PRZEGLAD SPAWALNICTWA. 2013. N 8. P. 36-40.

7. Magnusson H., Frisk K. Self-diffusion and impurity diffusion of hydrogen, oxygen, sulphur and phosphorus in copper. Swerea KIMAB AB.: Technical Report TR-13-24. Svensk Kärnbränslehantering AB, 2013. P.13-14. ISSN 1404-0344.

8. В. В. Чигарев, И. В.Серов, П. А. Гавриш [и др.] Исследование взаимодействия компонентов ванны при сварке деталей металлургического оборудования. Захист металургійних машин від поломок : зб.наук.пр. Маріуполь : ПДТУ, 2005. Вип. 8. С.214-223.

9. Гавриш П. А. Предотвращение образования кристаллизационных трещин при сварке меди со сталью. Нові конструкційні сталі та стопи і методи їх оброблення для підвищення надійності та довговічності виробів : Збірка матеріалів. Запоріжжя : ЗНТУ, 2005. С.77-79.

10. Пат. № 9352 Україна. МПК В23К 31/100. Спосіб визначення зварюваємості різнорідних металів. Гавриш П. А., Турчанін М. А., Кассов В. Д. Заявл. 25.03.2005; опубл. 15.09.2005; Бюл. № 9.

11. Gavrish P. A., Tulupov V. I. Perfection of the thermal cycle of copper with steel welding. The $11^{\text {th }}$ International Conference "Research and Development in Mechanical Industry",RaDMI. 2011. 15-18 Septemder. Sokobanja, Serbia. Vol. 1. P. 174-178

12. Гавриш П. А., Шепотько В. П. Влияние конструктивных особенностей сварных узлов перегружателя на его работоспособность. Автоматическая сварка. 2013. № 12. С. 51-54.

13. Пат. 75036 Україна, МПК В23 К 13/00. Спосіб зварювання різнорідних металів. Гавриш П. А., Тулупов В. І. № u201202789; заявл. 12.03.2012; опубл. 26.11.2012, Бюл. №. 22.

14. Gavrish P. A., Tulupov V. I. Preliminary heating at welding of copper with steel. The $10^{\text {th }}$ International Conference "Research and Development in Mechanical Industry" ( RaDMI 2010. In Memoriam of Prof. Dr. Georgios Petropoulos). Donji Milanovac: Serbia, 2010. Vol. 1, p. 156-158.

15. Гавриш П. А., Пыц Я. Е., Пыц В. Я. Деформационное упрочнение кромок при сварке меди со сталью. Обработка материалов давлением: сборник научных трудов. 2013. № 3 (36). С. 150-153. ISSN $2076-2151$.

\section{REFERENCES}

1. Rybin V.V., Wainerman A.E., Baranov A.V., Andronov E.V., Pichushkin S.A. Study of features and development of advanced technologies for welding copper alloys with steels and surfacing of copper alloys on steel. Scientific and technical journal (Materials Science Issues), L : LDNTP. 2006, 1, pp. 220-229 (in Russian).

2. Ilyushenko V.M., Bosak L.K., Grishin L.I., Lukyanchenko E.P. Automatic submerged arc welding large thicknesses. International Welding Association. Welding and surfacing of copper and its alloys. 2013. pp. 88-90. (in Russian). 
3. Oleksiak B., Siwiec G., Blacha A., Lipart J. Influence of iron on the surface tension of copper. Influence of iron on the surface tension of copper [Online]. Archives International Scientific Journal. 2010, 44. pp. $39-42$. $\mathrm{https} / / / \mathrm{www}$.google.com/search?q=Influence of iron on the surface tension of copper. International Scientific Journal.

4. Ding Weie. Heilogjiang kcji xueyuan xuebao. Institute of Science and Technology. 2003, V. 13, N4, pp. 16-18.

5. Arjun G., Atheena J. R., Nithin V. and others. Welding Feasibility of Copper and Mild Steel Using TIG Welding . Conference on Futuristic Advancements in Mechanical Engineering (FAME-2K16): Thalassery. 2016. August, pp. 325-326.

6. Pashkov I, Kustova O, Vetrova J. Phenomenon of interaction between the solder melts on the basis of copper and the steel detail surface. PRZEGLAD SPAWALNICTWA. 2013, 8, pp. 36-40. https://www.researchgate.net/publication/323333171.

7. Magnusson H. Frisk K.Self-diffusion and impurity diffusion of hydrogen, oxygen, sulphur and phosphorus in copper. Swerea KIMAB AB.: Technical Report TR-13-24. - Svensk Kärnbränslehantering AB, 2013, pp.13-14.

8. Chigarev V.V., Serov I.V., Gavrish P.A, Turchanin M.A., Kassov V.D. Study of the interaction of bath components in welding parts of metallurgical equipment. Protection of metallurgical machines from breakdowns. Interuniversity thematic collection of scientific works. 2005, 8, pp. 214-223 [in Russian].

9. Gavrish P.A. Prevention of the formation of crystallization cracks when welding copper with steel. New structural steels and soles and processing methods to improve the reliability and durability of products. Scientific collection. Zaporizhzhya. ZNTU. 2005, pp. S.77-79.

10. Gavrish P.A., Turchanin M.A., Kassov V.D. Method of determining weldability of heterogeneous metals. Patent. № 9352 Ukraine. September 15, 2005. (in Ukrainian).

11. Gavrish P.A., Tulupov V.I. Perfection of the thermal cycle of copper with steel welding. The $11^{\text {th }}$ International Conference "Research and Development in Mechanical Industry", RaDMI. Sokobanja, Serbia. 2011. Vol.1. pp. 174-178.

12. Gavrish P.A. Shepotko V.P. Influence of structural features of welding units of loaders on its efficiency. Avtomaticheskaya svarka. 2013, 12, pp. 51-54.

13. Gavrish P.A., Tulupov V.I. Method of welding heterogeneous metals. Patent Ukraine 75036. November 26, 2012. (in Ukrainian).

14. Gavrish P. A. Tulupov V.I. Preliminary heating at welding of copper with steel. The $10^{\text {th }}$ International Conference "Research and Development in Mechanical Industry" ( RaDMI 2010. In Memoriam of Prof. Dr. Georgios Petropoulos). : Donji Milanovac. Serbia, 2010,Vl.1. pp.156-158.

15. Gavrish P.A, Pyts Y.E, Pyts V.Y. Strain hardening edgesat the welding copper with steel. Materials work$\begin{array}{llll}\text { ing by } & \text { pressure. } & 2013, & 3(36) .\end{array}$ http://www.dgma.donetsk.ua/science_public/omd/omd 3(36)_2013/article/13gpacws.pdf [in Russian].

Гавриш П. А. - д-р техн. наук, доцент ДДМА; E-mail: nauka.breda@gmail.com

Грибков Е. П. - д-р техн. наук, доцент ДДМА; E-mail: gribkov.eduard@gmail.com

ДДМА - Донбаська державна машинобудівна академія, м. Краматорськ. 